\title{
Aid effectiveness and limited enforceable conditionality
}

\author{
Almuth Scholl* \\ University of Konstanz, Germany
}

\begin{abstract}
A B S T R A C T
This paper analyzes optimal foreign aid policy in a neoclassical growth framework with a conflict of interest between the donor and the recipient government. Aid conditionality is modeled as a limited enforceable dynamic contract. We define the contract to be selfenforcing if, at any point in time, the conditions imposed on aid funds are supportable by the threat of a permanent aid cutoff from then onward. Quantitative results show that optimal self-enforcing conditional aid strongly stimulates the developing economy and substantially increases welfare. However, aid effectiveness comes at a high cost: to ensure enforceability, less benevolent political regimes receive permanently larger aid funds in return for a less intense conditionality.
\end{abstract}

JEL classification:
E13
F35
011
019
Keywords:
Foreign aid
Conditionality
Limited enforceability
Dynarnic contracts
Neoclassical growth

\section{Introduction}

Foreign aid has been a substantial source of income in developing economies. As an example consider the case of Africa: on average aid funds amount to $11 \%$ of recipient's GDP. ${ }^{1}$ The stated intention of development assistance programs is to reduce poverty and to promote economic growth. However, the stagnating growth pattern in African countries calls the effectiveness of aid into question. ${ }^{2}$

This paper analyzes optimal foreign aid policy in a neoclassical growth framework with a conflict of interest between the donor and the recipient government. We take into account that, instead of implementing economic policies that coincide with the donor's intention, the recipient government may follow "bad" policies and use aid funds e.g. to assist political supporters or to finance military interventions. To prevent the government from doing so, it has become a common donor policy to impose conditions that specify how foreign aid funds should be allocated. However, since the recipient country is sovereign, its government may not be willing to keep the conditions.

The focus of this paper is to analyze the optimal design of incentive compatible aid conditionality. We follow the recent literature on limited commitment in dynamic macroeconomic settings and describe aid conditionality as an imperfectly enforceable dynamic contract between the donor and the recipient country. ${ }^{3}$ To ensure that the recipient government coop-

\footnotetext{
* Address for correspondence: University of Konstanz, Department of Economics, PO Box D 132, D-78457 Konstanz, Cermany. Fax: +49 (0) 7531884101. E-mail address: almuth,scholl@uni-konstanz.de.

1 Based on annual data from 1972 to 2000 and a sample of 33 sub-saharan African countries.

2 See e.g. Easterly et al. (2004), Easterly (2001) and the references therein, who do not find robust evidence that aid has led to increased growth.

${ }^{3}$ Papers that deal with limited enforceable dynamic contracts in different areas of research are e.g. Kocherlakota (1996), Kehoe and Levine (1993, 2001) Ligon et al. (2000), Alvarez and Jermann (2000), Cooley et al. (2004), Kehoe and Perri (2002), Krüger and Perri (2006) and Krüger and Uhlig (2006). In
} 
erates, the donor threatens with aid sanctions. Conditional aid policy is defined to be self-enforcing if, at any point in time, the conditions are supportable by the threat of a permanent aid cutoff from then onward.

Our paper builds on recent studies that analyze foreign aid policy in the light of incentive compatibility problems, in particular Cordella et al. (2003) and Kletzer (2005) who model conditional aid as an imperfectly enforceable contract in repeated agency models. Considering endowment economies, Cordella et al. (2003) focus on the connection of aid and debt relief while Kletzer (2005) stresses the credibility of aid sanctions. In contrast, this paper develops a neoclassical growth model to study the dynamic properties of optimal self-enforcing conditional aid policy and its impact on fiscal policy reforms and capital accumulation. In particular, our theoretical framework allows us to analyze the short-run properties of optimal aid policies during transitions paths as well as the long-run properties.

Our model focuses on the connection of aid, incentives and growth in the light of different political regimes in the recipient country. The developing economy is characterized by a government that finances unproductive government consumption by raising distortionary taxes and by using aid funds. While the donor cares solely about the welfare of the households, the recipient government may be non-benevolent. We define aid conditionality as an imperfectly enforceable dynamic contract that maximizes the donor's preferences subject to the optimal decision rules of the households and the government budget constraints. Thereby, the donor offers to transfer aid funds and, in return, expects the government to implement fiscal policy reforms that reduce the tax burden of the households.

We find that self-enforcing conditional aid strongly stimulates the economy as considerable tax cuts increase the incentives to invest in capital. Hence, aid flows foster economic growth and household consumption rises substantially implying large welfare gains. However, increasing household consumption comes at a high cost in the short- as well as the long-run, particularly in less benevolent political regimes. To ensure the enforceability of the aid contract, the donor has to pay large amounts of aid in return for a less intense conditionality. If aid transfers are not sufficiently high, a permanent aid cutoff does not pose a threat and the recipient government has no incentives to fulfill the conditions imposed by the donor. As a consequence, tax cuts are not implemented and aid has no or only minor impact on the developing economy. Since less benevolent recipient governments have lower incentives to implement the aid conditions, to ensure enforceability, the donor has to permanently transfer more aid to countries that suffer from less benevolent political regimes.

With respect to the dynamic short-run properties we find that optimal self-enforcing conditional aid is characterized by large transfers in the early periods to stimulate the economy. As capital grows, the amount of aid decreases until a long-run positive value of development assistance is reached. Importantly, aid cannot decrease to zero as the economy grows because that would induce the recipient government to break the aid conditions and to increase distortionary taxes.

The paper is structured as follows. Section 2 provides a comparison with the literature. In Section 3 a neoclassical framework is developed that considers different political regimes and allows us to analyze the effectiveness of aid programs in the light of enforceability problems. In Section 4 we discuss the calibration of the parameters. In Section 5 we analyze quantitatively the dynamic properties and the effectiveness of self-enforcing conditional aid by studying transition paths and long-run properties. Moreover, we compare the impact of conditional aid as opposed to unconditional aid. Finally, Section 6 concludes with some critical remarks and an outlook on future research.

\section{Comparisons with the literature}

There is an ongoing major debate about how aid agencies should design aid programs, primarily based on empirical evidence. However, the empirical literature concerning the impact of foreign aid on growth and the connection between aid effectiveness and recipient's economic policies is controversial: there seems to be no robust evidence concerning the interaction of foreign aid, sound economic policies and growth. ${ }^{4}$

Rather than drawing on empirical arguments, the objective of our study is to contribute to the debate by theoretically deriving implications for optimal conditional foreign aid policy. The theoretical literature on aid effectiveness is limited and there are two main directions: the first direction focuses on the impact of aid on growth while the second emphasizes incentive compatibility problems.

To study the link between aid and economic growth, studies of the first direction take aid flows as exogenously given, e.g. Chenery and Strout (1966), Chatterjee et al. (2003), Dalgaard et al. (2004) and Mourmoras and Rangazas (2006). ${ }^{5}$ Svensson (1999) and Boone (1996) account for distortions within the recipient country and study the impact of unconditional aid in the presence of different political institutions. The latter shows that the effectiveness of unconditional aid is very limited in the presence of less democratic political regimes. ${ }^{6}$

\footnotetext{
particular, Marcet and Marimon (1992) analyze external financing opportunities under limited commitment in a stochastic growth model. In Giovannetti et al. (1993) the theoretical model developed in Marcet and Marimon (1992) is applied to the case of Africa. This paper is also related to the sovereign debt literature, see e.g. Kletzer and Wright (2000) and the references therein.

4 See e.g. Burnside and Dollar (2000, 2004), Hansen and Tarp (2000, 2001), Dalgaard and Hansen (2001), Guillaumont and Chauvet (2001), Lensink and White (2001), Devarajan et al. (2000), Collier and Dollar (2001, 2002), Easterly et al. (2004) and Easterly (2003).

5 Studies like e.g. Arellano et al. (2009) study the effects of aid and its volatility and focus mainly on the short-run fluctuations in the developing economy.

6 Most papers in this area of research focus on distortions within the recipient country. One exception is Dalgaard (2008) who analyzes to what extent donor policies influence the effectiveness of aid.
} 
Adam and O'Connell (1999) and Coate and Morris (1995) belong to the first papers that point out that conditionality can be interpreted as contracts between donors and recipient governments. The second direction of research focuses on this feature and uses stylized game-theoretic models to study aid effectiveness in the light of incentive compatibility, moral hazard and informational problems. Most papers in this literature assume static or simple two-period frameworks. There are two main issues raised. On the one side, Murshed and Sen (1995), Svensson (2000a, 2000b, 2003), Pedersen (1996, 2001), Federico (2001) and Hagen (2006) focus on the time inconsistency of the donor's behavior as explanation for limited aid effectiveness since policy conditionality is often criticized for a lack of credibility. In this literature the Samaritan's Dilemma is emphasized: the expectation of aid funds can lead countries to behave in a way that keeps them in poverty. Federico (2001) shows that there exists an inverse link between aid and reform. He argues that the Samaritan's Dilemma is more relevant for more altruistic donors which makes reforms more costly in return for less intense conditionality. On the other side, Azam and Laffont (2003), Cordella et al. (2003) and Kletzer (2005) focus on limited commitment on the side of the recipient's government given that the donor is altruistic while the recipient government is selfish.

This paper attempts to link the two directions of research by analyzing conditional aid and incentive compatibility issues in a dynamic neoclassical growth model to study how transfers affect savings and capital accumulation. Our model framework is similar to the one in Boone (1996), however, he focuses on exogenous unconditional aid and limits the analysis to steady states while we determine self-enforcing conditional aid endogenously and analyze the short-run as well as the long-run properties. Mourmoras and Rangazas (2006) also develop a neoclassical growth model that incorporates different sources of poverty to study the impact of foreign aid. They calculate the costs of 'buying' fiscal policy reforms in the developing economy and, similarly to our paper, find that these costs are high. However, in our theoretical framework, donors optimally choose incentive-compatible aid policies over time whereas Mourmoras and Rangazas (2006) exogenously assume a constant aid stream that makes the recipient government indifferent to the fiscal policy reform.

Our theoretical framework aims to shed light on the conflict of interest between the donor and the government and the associated incentive problems but abstracts from important sources of poverty such as fertility, human capital, etc. We concentrate our analysis on limited commitment on the side of the recipient's government. We discuss the important question of credibility and limited commitment on the donor's side in the concluding Section 6.

\section{The model}

In the following we develop a neoclassical growth framework to analyze the connection of aid, incentives and growth in the light of different political regimes in the recipient country. Our model builds on four major assumptions. First, the intention of foreign aid programs is poverty reduction. It may be interesting to analyze objectives that are more of political nature, however, this is beyond the scope of this paper. Second, recipient countries may have non-benevolent political regimes such that a conflict of interest between the donor and the recipient government is generated. Third, the conditions imposed on aid funds are imperfectly enforceable while donors fully commit to their policies. Fourth, foreign aid flows do not change the institutions in the recipient country, i.e. donors take the political regime as given when designing aid policy.

\subsection{The environment}

We consider a developing economy inhabited by a large number of infinitely-lived households who maximize utility. There is a government who finances its unproductive consumption by raising distortionary taxes on households' income and by using foreign aid funds.

Preferences of the representative household are given by

$$
\sum_{t=0}^{\infty} \beta^{t} u\left(c_{t}\right), \quad 0<\beta<1,
$$

where $c_{t}$ denotes household consumption at time $t$. The utility function $u\left(c_{t}\right)$ satisfies $u^{\prime}\left(c_{t}\right)>0$ and $u^{\prime \prime}\left(c_{t}\right)<0$. The households' budget constraint is given by

$$
c_{\mathrm{t}}+k_{t}=\left(1-\tau_{\mathrm{t}}\right) y_{t}+(1-\delta) k_{\mathrm{t}-1} \text {, }
$$

$k_{-1}>0$. The capital stock at time $t$ is denoted by $k_{t}$, production $y_{t}$ is given by a constant returns to scale production function, $y_{t}=F\left(k_{t-1}, n_{t}\right)$, and $\tau_{t}$ denotes the income tax rate raised by the government. $0 \leqslant \delta \leqslant 1$ is the capital depreciation rate. In the following we normalize labor $n_{t} \equiv 1$, for all $t$, such that $F\left(k_{t-1}, 1\right) \equiv f\left(k_{t-1}\right)$.

Preferences of the government are given by

$$
\sum_{t=0}^{\infty} \beta^{t}\left[\alpha u\left(c_{t}\right)+(1-\alpha) v\left(g_{t}\right)\right]
$$

\footnotetext{
7 This assumption is in line with empirical findings: Dollar and Svensson (2000) and the references therein do not find robust evidence that foreign aid has a positive impact on institutions or reforms.
} 
where the utility function $v$ satisfies $v^{\prime}\left(g_{t}\right)>0$ and $v^{\prime \prime}\left(g_{t}\right)<0$. We label unproductive government consumption by $g_{t}$ and interpret it as e.g. expenditures supporting the political elite. $\alpha \in(0,1)$ measures the benevolence of the government and is interpreted as an indicator of the political regime in the recipient country. If $\alpha=1$ there is no government consumption, and, hence, there are no distortions in the economy.

The government's budget constraint is given by

$$
g_{t}=\tau_{t} y_{t}+a_{t},
$$

where $a_{t} \geqslant 0$ denotes aid transfers given by the donor.

The representative donor makes costly aid transfers. The donor's preferences are dependent on the welfare of the households and are given by

$$
\sum_{t=0}^{\infty} \beta^{t}\left[u\left(c_{t}\right)-h\left(a_{t}\right)\right]
$$

where the cost function $h\left(a_{t}\right)$ satisfies $h\left(a_{t}\right)>0$ for $a_{t}>0$ and $h\left(a_{t}\right)=0$ for $a_{t}=0$. Moreover, $h^{\prime}\left(a_{t}\right)>0$ and $h^{\prime \prime}\left(a_{t}\right) \geqslant 0$.

\subsection{Unconditional aid}

Given taxes and government consumption households maximize (1) subject to their budget constraint (2). The competitive equilibrium is characterized by

$$
u^{\prime}\left(c_{t}\right)=\beta u^{\prime}\left(c_{t+1}\right)\left[1-\delta+\left(1-\tau_{t+1}\right) f^{\prime}\left(k_{t}\right)\right]
$$

together with the budget constraints of the households and the government, (2) and (4), and with $y_{t}=f\left(k_{t-1}\right)$. Eq. (6) is the usual Euler equation that connects the marginal rate of substitution between consumption today and tomorrow with the rate of return $\left[1-\delta+\left(1-\tau_{t+1}\right) f^{\prime}\left(k_{t}\right)\right]$.

Without any conditions imposed on foreign aid funds the recipient government chooses taxes and government consumption, such that government's preferences are maximized subject to the government budget constraint and the competitive equilibrium:

$$
\max _{\left\{c_{t}, g_{t}, k_{t}\right\}_{t=0}^{x}} \sum_{t=0}^{\infty} \beta^{t}\left[\alpha u\left(c_{t}\right)+(1-\alpha) v\left(g_{t}\right)\right]
$$

s.t.

$$
\text { (2), (4) and (6) }
$$

given $k_{-1}>0$.

Suppose that the political regime is characterized by a high value of $\alpha$. Since the recipient government is highly benevolent, aid funds are used to decrease the distortionary tax on households' income such that investment increases and the economy is stimulated. In contrast, for low values of $\alpha$ the recipient government uses large parts of aid funds to increase government consumption.

The optimality conditions are:

$$
\begin{aligned}
& \zeta_{t}=\alpha u^{\prime}\left(c_{t}\right)+u^{\prime \prime}\left(c_{t}\right)\left(\lambda_{t-1}\left[1-\delta+\left(1-\tau_{t}\right) f^{\prime}\left(k_{t-1}\right)\right]-\lambda_{t}\right) \\
& \zeta_{t}=(1-\alpha) v^{\prime}\left(g_{t}\right)-\lambda_{t-1} u^{\prime}\left(c_{t}\right) \frac{f^{\prime}\left(k_{t-1}\right)}{f\left(k_{t-1}\right)} \\
& \frac{\zeta_{t}}{\beta}=\zeta_{t+1}\left(f^{\prime}\left(k_{t}\right)+1-\delta\right)+\lambda_{t} u^{\prime}\left(c_{t+1}\right)\left(\left(1-\tau_{t+1}\right) f^{\prime \prime}\left(k_{t}\right)+\tau_{t+1} \frac{\left[f^{\prime}\left(k_{t}\right)\right]^{2}}{f\left(k_{t}\right)}\right)
\end{aligned}
$$

and (2), (4) and (6). $\lambda_{t}$ denotes the Lagrange multiplier on the Euler equation of the households (6) and enters as a state variable. $\zeta_{t}$ is the multiplier associated with the household budget constraint. The first order conditions with respect to household consumption and government consumption, (8) and (9), show that optimal household consumption and government consumption connect the cost $\zeta_{t}$ of a marginal increase in consumption with the weighted marginal utility $\alpha u^{\prime}\left(c_{t}\right)$ and $(1-\alpha) v^{\prime}\left(g_{c}\right)$, respectively. Eq. (10) is the first order condition with respect to capital and is standard in the Ramsey approach to optimal taxation.

Let $\mathbf{a}_{0}$ denote the whole sequence of aid starting at time zero and define $D\left(a_{0}, k_{-1}\right)$ to be the solution to the government's maximization problem (7) characterized by (2), (4), (6) and (8) to (10).

\subsection{Conditional aid as self-enforcing contract}

Donors want to choose aid policies that induce the government to devote aid funds to policies that coincide with the donor's intention. To do so, it has become common to impose conditions on aid funds. The crucial question is how to design 
incentive compatible conditionality. We define aid conditionality as a dynamic contract between the donor and the recipient country that specifies foreign aid and tax policies in such a way that the donor's preferences are maximized subject to the competitive equilibrium and the government budget constraints. However, the contract is imperfectly enforceable since the sovereign recipient government can always dishonor the conditions and implement ineffective tax policies. We assume that in this case the donor responds with aid sanctions.

In the following we assume that conditional foreign aid policy constitutes a self-enforcing contract between the donor and the recipient government only if, at any point in time, the conditions are supportable by the threat of permanent aid sanctions from then onwards. Aid conditions are defined to be feasible only if, at any point in time, the government's utility of fulfilling the conditions is larger than the utility in case of a permanent aid cutoff. Note that we assume that the threat is fully credible and that there is full commitment on the donor's side. Since a permanent aid cutoff is the worst possible scenario for the recipient government, the associated self-enforcing allocation is the best the donor can achieve.

The self-enforcing contract is defined to be given by the solution to the following maximization problem of the donor:

$$
\begin{aligned}
& \max _{\substack{\left.c_{t}, g_{t}, k_{t}, a_{t}\right\}_{t=0}^{\infty} \\
\text { s.t. }}}^{\infty} \sum_{t=0}^{\infty} \beta^{t}\left[u\left(c_{t}\right)-h\left(a_{t}\right)\right] \\
& \sum_{j=0}^{\infty} \beta^{j}\left[\alpha u\left(c_{t+j}\right)+(1-\alpha) v\left(g_{t+j}\right)\right] \geqslant D\left(\mathbf{0}, k_{t-1}\right)
\end{aligned}
$$

$$
\text { (2). (4) and (6) }
$$

given $k_{-1}>0 . D\left(0, k_{t-1}\right)$ is the solution to the government's maximization problem (7) if no foreign aid funds are given from $t$ onwards. Note that default is chosen before receiving the current aid $a_{t}$. Even if the consequence of default is a permanent cutoff of development assistance, the recipient country is still endowed with the capital that has been built up using past aid payments. Sovereignty ensures that the capital stock cannot be seized by the donor. The solution to (11) is an allocation $\left\{c_{t}, g_{t}, k_{t}\right\}_{t=0}^{\infty}$ and policy actions $\left[a_{t}, \tau_{t}\right\}_{t=0}^{\infty}$ that can be interpreted as the outcome of aid conditionality. The donor offers to transfer $a_{t}$ at time $t$ and in return expects the recipient government to implement the fiscal policy action $\tau_{t}$ that is associated with the allocation $\left\{c_{t}, g_{t}, k_{t}\right\}_{t=0}^{\infty}$.

The maximization problem (11) contains the enforcement constraint (12) that includes future realizations of the decision variables. To solve the problem we follow Marcet and Marimon $(1992,1998)$ and introduce an additional co-state variable $\mu_{i}$ that measures the binding pattern of the enforcement constraint. If the enforcement constraint is not binding at time $t$, $\mu_{t}$ is determined by past binding patterns, $\mu_{t}=\mu_{t-1}$. If the enforcement constraint is binding at time $t, \mu_{t}>\mu_{t-1}$. The donor's maximization problem (11) can be transformed into the following saddle-point formulation:

$$
\begin{aligned}
& \min _{\left\{\mu_{t} \geqslant \mu_{t-1}\right\}_{t=0}^{\infty}\left(c_{t}, g_{t}, k_{t}, a_{t}\right\}_{t=0}^{\infty}} \sum_{t=0}^{\infty} \beta^{t}\left[u\left(c_{t}\right)-h\left(a_{t}\right)+\mu_{t}\left(\alpha u\left(c_{t}\right)+(1-\alpha) v\left(g_{t}\right)\right)\right. \\
& \left.-\left(\mu_{t}-\mu_{t-1}\right) D\left(0, k_{t-1}\right)\right]
\end{aligned}
$$

s.t.

(2), (4) and (6).

This formulation shows clearly that the additional co-state variable $\mu_{t}$ enters as a weight on government's preferences.

The optimal allocation associated with the self-enforcing aid contract (13) satisfies the following conditions

$$
\begin{aligned}
\zeta_{t}= & \left(1+\alpha \mu_{t}\right) u^{\prime}\left(c_{t}\right)+u^{\prime \prime}\left(c_{t}\right)\left(\lambda_{t-1}\left[1-\delta+\left(1-\tau_{t}\right) f^{\prime}\left(k_{t-1}\right)\right]-\lambda_{t}\right) \\
\zeta_{t}= & (1-\alpha) \mu_{t} v^{\prime}\left(g_{t}\right)-\lambda_{t-1} u^{\prime}\left(c_{t}\right) \frac{f^{\prime}\left(k_{t-1}\right)}{f\left(k_{t-1}\right)} \\
-\zeta_{t}= & -h^{\prime}\left(a_{t}\right)+\lambda_{t-1} u^{\prime}\left(c_{t}\right) \frac{f^{\prime}\left(k_{t-1}\right)}{f\left(k_{t-1}\right)} \\
\frac{\zeta_{t}}{\beta}= & \zeta_{t+1}\left(f^{\prime}\left(k_{t}\right)+1-\delta\right)+\lambda_{t} u^{\prime}\left(c_{t+1}\right)\left(\left(1-\tau_{t+1}\right) f^{\prime \prime}\left(k_{t}\right)+\tau_{t+1} \frac{\left[f^{\prime}\left(k_{t}\right)\right]^{2}}{f\left(k_{t}\right)}\right) \\
& \quad-\left(\mu_{t+1}-\mu_{t}\right) D^{\prime}\left(\mathbf{0}, k_{t}\right) \\
0= & \left(\mu_{t}-\mu_{t-1}\right)\left(\sum_{j=0}^{\infty} \beta^{j}\left[\alpha u\left(c_{t+j}\right)+(1-\alpha) v\left(g_{t+j}\right)\right]-D\left(\mathbf{0}, k_{t-1}\right)\right)
\end{aligned}
$$

together with (2), (4) and (6). $\lambda_{t}$ denotes the Lagrange multiplier on the Euler equation and measures its tightness. $\zeta_{t}$ is the Lagrange multiplier of the budget constraint. Eq. (18) is the complementary slackness condition. 
The constraints (2), (4) and (6), the optimality conditions (14) to (17) and the complementary slackness condition (18) form a system of highly nonlinear equations that depend on the state variables $k_{t}, \lambda_{t}$ and $\mu_{t}$. Since no analytical closedform solution can be derived, we solve the model numerically to study transition paths and steady states. Before doing so, we have a closer look at the optimality conditions to give some qualitative insights about the properties of self-enforcing conditional aid policy.

First, note that the first order conditions of the donor with respect to $c_{t}$ and $g_{t}$ given by (14) and (15) are similar to those of the government (8) and (9). They differ only in the weight on households' utility $u\left(c_{(t)}\right)$ and government's utility $v\left(g_{t}\right)$. Initially, the donor puts full weight on households' utility while government's preferences are characterized by a weight $\alpha$ on $u\left(c_{t}\right)$ and $(1-\alpha)$ on $v\left(g_{t}\right)$. Over time, the donor's weight on households' and government's utility is dependent on the co-state variable $\mu_{t}$ that measures the binding pattern of the enforcement constraint. Note that $\mu_{t}$ is a non-decreasing accumulative Lagrange multiplier: if the government has an incentive to default on the aid conditions, $\mu_{t}$ increases and the weights $\left(1+\alpha \mu_{t}\right)$ and $(1-\alpha) \mu_{t}$ rise. Hence, household consumption and government consumption are non-decreasing over time. How strongly household consumption and government consumption are affected by $\mu_{t}$ depends on the value of $\alpha$. Consider the extreme case $\alpha=0$ : then $\mu_{t}$ enters solely as a weight on government utility.

For a given $\alpha$, the strength of the binding pattern of the enforcement constraint at time $t$ is crucially determined by the capital stock $k_{t-1}$. Since government's preferences fulfill the usual assumptions, the outside option is increasing in capital, $D^{\prime}\left(\mathbf{0}, k_{t-1}\right)>0$. Hence, $\mu_{t}$ is non-decreasing in capital. Eq. (17) is the first order condition with respect to capital. A marginal increase in capital at time $t$ raises the outside option at time $t+1$ and influences the future binding pattern of the enforcement constraint which is captured by the term $-\left(\mu_{t+1}-\mu_{t}\right) D^{\prime}\left(\mathbf{0}, k_{t}\right)$.

Substituting Eq. (15) in (16) yields

$$
h^{\prime}\left(a_{t}\right)=(1-\alpha) \mu_{t} v^{\prime}\left(g_{t}\right)
$$

Eq. (19) determines optimal foreign aid $a_{t}$ by equating marginal costs of aid and weighted marginal utility of government consumption. Recall that government consumption $g_{t}$ is increasing in $\mu_{t}$. Given the assumptions on $h\left(a_{t}\right)$, as long as $v^{\prime}\left(g_{t}\right)$ declines more than $\mu_{t}$ increases over time, aid is decreasing over time.

Since there exists a finite constant $\bar{D}$ such that $\bar{D}>D\left(0, k_{t-1}\right), \mu_{t}$ will grow until it reaches a level such that $\sum_{j=0}^{\infty} \beta^{j}\left[\alpha u\left(c_{t+j}\right)+(1-\alpha) v\left(g_{t+j}\right)\right] \geqslant \bar{D}$. The enforcement constraint will never be binding again such that the co-state variable will be constant from then onwards, $\mu_{t}=\bar{\mu}$. Thus, from then onwards, the donor's maximization problem is a standard Ramsey problem with fixed utility weights $(1+\alpha \bar{\mu})$ and $(1-\alpha) \bar{\mu}$. Since the model assumes no exogenous growth, we suppose that the economy converges to a steady state that is characterized by a constant weight $\bar{\mu}$, a constant allocation $(\bar{c}, \bar{g}, \bar{k})$ and constant policy $(\bar{\tau}, \bar{a})$ that fulfill the optimality conditions (14) to (18) together with the constraints (2). (4) and (6).

\section{Calibration}

We assume logarithmic utility functions: $u(\cdot)=v(\cdot)=\log (\cdot)$. The production function is considered to be $f\left(k_{t-1}\right)=k_{t-1}^{\theta}$, where $0<\theta<1$ denotes the capital share. The donor's cost function $h\left(a_{t}\right)$ is assumed to be quadratic, $h\left(a_{t}\right)=\kappa a_{l}^{2}$, where $\kappa>0$ is a parameter.

The first column of Table 1 presents the mean value of aid as percentage of recipient's GDP between 1972 and 2000 . As a measure of foreign aid we use the definition of the Development Assistance Committee of the OECD that views aid as the sum of nonmilitary grants and concessional loans net of repayment of previous aid loans, called total net official Development Assistance (ODA). The table reveals that all countries in our sample received aid flows, varying between 2 and 30 percent of GDP. With respect to the cost function $h\left(a_{l}\right)$ we calibrate $\kappa$ such that for $\alpha=0.5$ the steady state foreign aid share is 10 percent which is the median in the data. Calibrating $\kappa$ differently leads to qualitatively similar results.

Recently. Gollin (2002) argues that the usual calculation of labor shares using employee compensation as a fraction of GDP fails to account for labor income of the self-employed which is particularly important in poor countries. Gollin (2002) shows that if self-employment is taken into account, estimated labor shares fall in the range of 0.65 and 0.80 for most countries. Therefore, we follow e.g. Gourinchas and Jeanne (2008) and use $\theta=0.3$ in our benchmark calibration which is consistent with the value commonly used in the neoclassical growth model. In our theoretical setup, suppose that no aid is given to the developing country. Then, for $\theta=0.3$ the steady state investment share varies between 10 and 16 percent, depending on the value of $\alpha$. The third column of Table 1 reveals that this seems to be reasonable for around half of the considered African countries that have investment share well below 20 percent. However, the remaining countries in our sample are characterized by investment shares larger than 20 percent. Moreover, for e.g. Mauritius Gollin (2002) estimates a labor share of 0.49 . Therefore, we additionally consider $\theta=0.5$ such that steady state investment shares vary between 20 and 28 percent. This calibration is in line with e.g. Giovannetti et al. (1993) and matches the conventional view that developing countries have higher capital shares.

There are no easy ways to calibrate the parameter $\alpha$ that measures the benevolence of the recipient government. Therefore the paper tries different values of $\alpha$ to reflect different degrees of distortions.

The remaining parameters are calibrated on an annual basis. For the discount factor and the capital depreciation rate we assume values that are consistent with the usual neoclassical growth model, $\beta=0.96$ and $\delta=0.10$. 
Table 1

Aid and investment in sub-saharan Africa.

\begin{tabular}{|c|c|c|}
\hline Country & Aìd share & Investment share \\
\hline Benin & 10.06 & 16.74 \\
\hline Botswana & 8.68 & 28.20 \\
\hline Burkina Faso & 15.45 & 22.49 \\
\hline Burund! & 15.67 & 12.29 \\
\hline Cameroon & 4.04 & 19.20 \\
\hline Central Afr. Rep. & 13.27 & - \\
\hline Chad & 13.09 & - \\
\hline Congo & 6.62 & 26.91 \\
\hline Cote d'Ivoire & 4.38 & 16.31 \\
\hline Egypt & 6.12 & 23.30 \\
\hline Gabon & 2.11 & 34.60 \\
\hline Gambia & 25.65 & - \\
\hline Ghana & 6.07 & 11.57 \\
\hline Guinea Bissau & 24.63 & 23.34 \\
\hline Kenya & 7.65 & 21.07 \\
\hline Lesotho & 20.54 & - \\
\hline Madagascar & 9.25 & 12.74 \\
\hline Malawi & 20.36 & 17.07 \\
\hline Malí & 18.47 & 20.41 \\
\hline Mauritius & 2.75 & 25.06 \\
\hline Morocco & 2.91 & 22.49 \\
\hline Niger & 13.82 & 15.35 \\
\hline Nigeria & 0.32 & 13.71 \\
\hline Rwanda & 17.21 & 13.69 \\
\hline Senegal & 11.16 & 13.13 \\
\hline Seychelles & 8.89 & 28.41 \\
\hline Sierra Leone & 12.85 & 9.87 \\
\hline Swaziland & 6.27 & 27.44 \\
\hline Tanzania & 15.38 & 20.48 \\
\hline Togo & 10.07 & 21.90 \\
\hline Tunisia & 2.72 & 26.01 \\
\hline Zambia & 29.99 & 17.06 \\
\hline Zimbabwe & 4.02 & 18.90 \\
\hline
\end{tabular}

Notes: Data are annual from the OECD and IMF from 1972 to 2000 . Foreign aid is measured by Net Official Development Assistance. Aid and investment are presented as shares of recipient's GDP. Entries are mean values. Data on investment are limited for Botswana (1974-2000), Cameroon (1972-1997), Cote d'Ivoire (1972-1997), Gabon (1972-1998), Ghana (1972-1997), Guinea Bissau (1986-1997), Mali (1981-2000), Senegal (1972-1998), Seychelles (1976 1998), Zimbabwe (1972-1997) and Zambia (1985-1997).

The absence of uncertainty implies that the enforcement constraint is always binding until the steady state is reached. Therefore, we employ a backward procedure to solve for the transitional dynamics. The details of the algorithm are described in Appendix A.

\section{Quantitative properties of aid policies}

We structure the description of the results as follows. In Section 5.1 we first analyze the economic outcome of different political regimes that receive no development assistance. Section 5.2 studies the characteristics of optimal foreign aid policy if the donor is able to perfectly enforce $g_{t}=0$, independently of the political regime. This is our benchmark aid policy since this is the best that the donor can achieve. Section 5.3 analyzes the quantitative short and long-run characteristics of optimal self-enforcing conditional aid flows. We compare the effectiveness of conditional and unconditional aid in Section 5.4. Finally, Section 5.5 considers aid effectiveness in the presence of a larger capital share parameter.

\subsection{No aid}

To study the effectiveness of foreign aid, we first analyze the situation of a developing country that receives no foreign aid funds. We focus on the impact of different political regimes on the overall economy.

Without any development assistance the government in the developing country chooses income tax rates and government consumption by solving the maximization problem (7) with $a_{t}=0$ for all $t$. We consider different political regimes and summarize the steady state values of the main economic indicators in Table 2, panel 1 . In the following we refer to this scenario as the 'No Aid' steady state.

First, consider a government that puts a large weight on the welfare of the households, $\alpha=0.7$, but also finances some unproductive government consumption by raising a distortionary tax on households' income. In the steady state the income tax rate amounts to 24 percent to finance a 24 percent government consumption share. The household consumption share and the investment share are 60 and 16 percent, respectively. A government that puts a lower weight on the welfare of the households, $\alpha=0.5$, increases its government consumption share by increasing the income tax rate to 39 percent. The 
Table 2

Steady state properties of foreign aid policies.

\begin{tabular}{|c|c|c|c|c|c|c|c|c|c|}
\hline & $\bar{a}$ & $\overline{\bar{\tau}}$ & $\bar{c}$ & $\bar{g}$ & $\bar{k}$ & $\frac{a}{y}$ & $\frac{\vec{c}}{y}$ & $\bar{y}$ & $\frac{\bar{x}}{\bar{y}}$ \\
\hline \multicolumn{10}{|l|}{ I. No Aid } \\
\hline$\alpha=0.7$ & 0 & 0.24 & 0.74 & 0.29 & 1,99 & 0 & 0.60 & 0.24 & 0.16 \\
\hline$\alpha=0.5$ & 0 & 0.39 & 0.53 & 0.44 & 1.43 & 0 & 0.48 & 0.39 & 0.13 \\
\hline$\alpha=0.3$ & 0 & 0.55 & 0.35 & 0.54 & 0,93 & 0 & 0.35 & 0.55 & 0,10 \\
\hline \multicolumn{10}{|c|}{$\begin{array}{l}\text { 11. Benchmark } \\
\text { Aid Policy } A\end{array}$} \\
\hline all $\alpha$ & 0 & 0 & 1.09 & 0 & 2.92 & 0 & 0.79 & 0 & 0.21 \\
\hline \multicolumn{10}{|c|}{$\begin{array}{l}\text { III. Self-Enforcing Conditional Aid } \\
\text { Aid Policy B }\end{array}$} \\
\hline$\alpha=0.7$ & 0.11 & 0.03 & 1.05 & 0.15 & 2.81 & 0.08 & 0.76 & 0.11 & 0.21 \\
\hline$\alpha=0.5$ & 0.13 & 0.12 & 0.91 & 0.28 & 2.44 & 0.10 & 0.70 & 0.22 & 0.18 \\
\hline$\alpha=0.3$ & 0.15 & 0.22 & 0.76 & 0.43 & 2.03 & 0,12 & 0.61 & 0.34 & 0.17 \\
\hline \multicolumn{10}{|c|}{$\begin{array}{l}\text { IV. Unconditional Aid } \\
\text { Aid Policy B }\end{array}$} \\
\hline$\alpha=0.7$ & 0.11 & 0.18 & 0.82 & 0.33 & 2.22 & 0.09 & 0.65 & 0.26 & 0.18 \\
\hline$\alpha=0.5$ & 0.13 & 0.34 & 0.60 & 0.52 & 1.62 & 0.12 & 0.52 & 0.45 & 0.14 \\
\hline$\alpha=0.3$ & 0.15 & 0.51 & 0.40 & 0.67 & 1.06 & 0.15 & 0.39 & 0.66 & 0.10 \\
\hline
\end{tabular}

Notes: $\vec{a}, \bar{z}, \bar{c}, \bar{g}, \bar{k}$ and $\bar{y}$ denote the steady state values of aid, tax, household consumption, government consumption, capital and output, respectively. Aid Policy A' assumes that the donor can perfectly enforce $g_{t}=0, \forall t$. 'Aid Policy B' is the outcome of the donor's maximization problem (11).

households have lower incentives to invest, such that the steady state capital stock decreases from 1.99 to 1.43 . In the least benevolent political regime, $\alpha=0.3$, income taxes of 55 percent decrease the capital stock and consumption to a very low level. This political scenario is characterized by a government consumption share that is larger than the private consumption share.

The results indicate that developing countries with non-benevolent governments suffer from low levels of capital and consumption due to strong distortions generated by the government. In the following we analyze to what extent foreign aid policy helps to improve the economic situation of developing countries. We assume that the donor observes the 'No Aid' steady state capital stocks as the initial situations.

\subsection{Benchmark}

Before we turn to the analysis of limited enforceable conditionality, we first construct a scenario that assumes that the donor can perfectly enforce the conditions imposed on aid. In particular, suppose, at any point in time, the donor can impose $g_{t}=0$ and the recipient government cannot reject this condition. Since $g_{t}=0$, the tax on income is given by $\tau_{t}=-a_{t} / y_{t}$ and can be understood as a subsidy. We refer to this scenario as 'Aid Policy $A$ ' and consider it as our benchmark of the effectiveness of foreign aid since this is the best the donor can achieve in our theoretical setup.

Given the 'No Aid' steady state capital stocks as initial situation, Fig. 1 plots optimal aid transfers, the associated tax policy, household and government consumption, capital and investment. All variables are normalized by their respective 'No Aid' steady state values, except foreign aid that is normalized by the 'No Aid' steady state value of output.

The graphs show that optimal foreign aid policy is characterized by temporary transfers to stimulate the economy on its transition path to the steady state associated with $\bar{g}=0$. On impact, the amount of aid yields a subsidy that can be interpreted as an e.g. approximately three percent increase in productivity for $\alpha=0.3$. The subsidy raises households' incentives to invest in capital. As capital grows, aid funds revert to zero, such that in the long-run $\bar{\tau}=0$. The economy with the least benevolent political regime, $\alpha=0.3$, receives the largest development assistance because it is the poorest country with the lowest initial capital stock. The economy characterized by $\alpha=0.7$ gets low development assistance since the 'No Aid' steady state capital stock is close to the efficient one. Since the economy associated with $\alpha=0.3$ receives the largest payment and the tax cut is the biggest, investment (and capital) increases most in relative terms. Household consumption can be considerably increased. Because the donor can enforce $g_{t}=0$, independently of the political regime, the three economies converge to the same new steady state summarized in panel II of Table 2 . The steady state is characterized by a private consumption share of 79 percent and an investment share of 21 percent.

Panel I of Table 3 presents the impact of 'Aid Policy $A$ ' on welfare. For reasons of interpretation we use compensating variations to formulate differences in lifetime utility and express the welfare gain in terms of percentage deviation in certainty-equivalence consumption relative to the 'No Aid' steady state. For example households' consumption equivalents $\Delta$ can be calculated as

$$
\sum_{t=0}^{\infty} \beta^{t} u\left((1+\Delta) \bar{c}^{\text {no aid }}\right)=\sum_{t=0}^{\infty} \beta^{t} u\left(c_{t}\right) .
$$



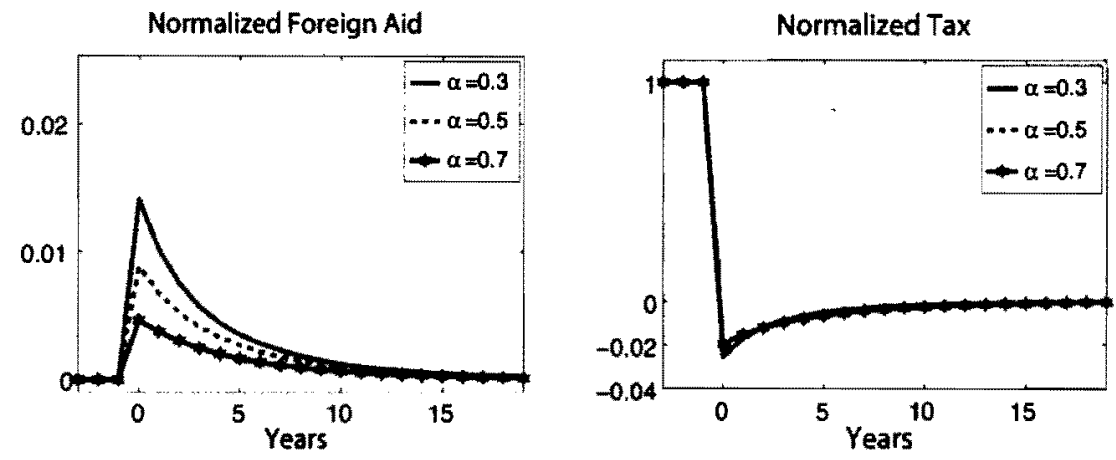

Normalized Household Consumption

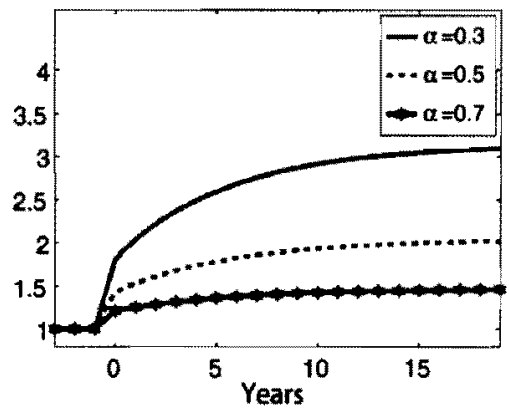

Normalized Government Consumption

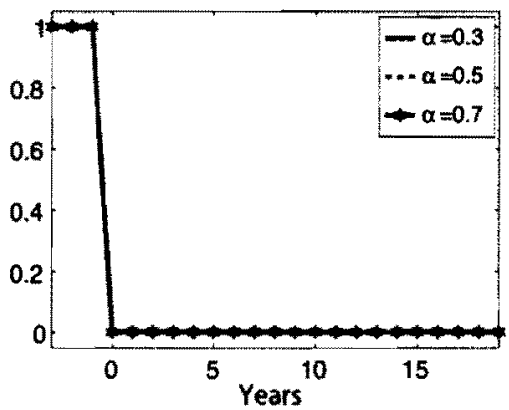

Normalized investment
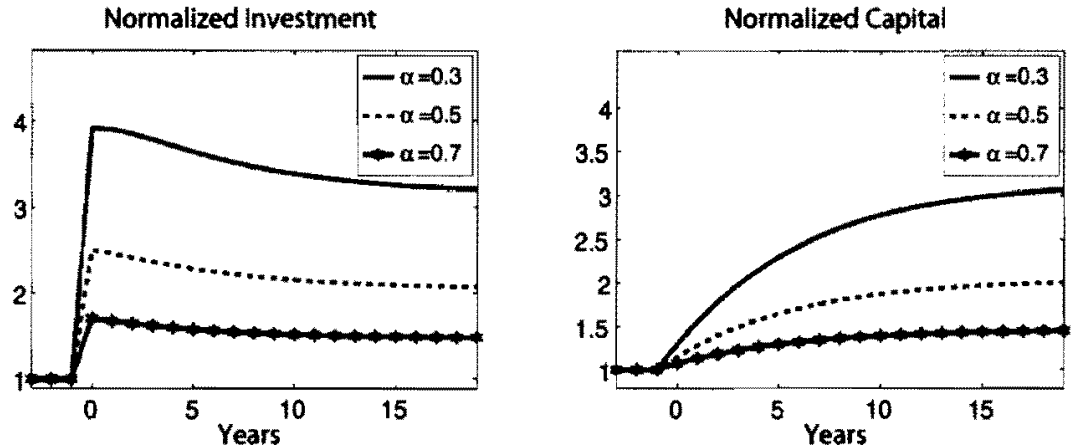

Notes: This figure shows optimal foreign aid policy given that the donor can perfectly enforce $g_{t}=0 \forall t$. The initial capital stock is assumed to be the "No Aid" steady state capital stock. The tax rate, household consumption, government consumption, investment and capital are normalized by their respective 'No Aid' steady state values. Aid is normalized by the 'No Aid' steady state value of output.

Fig. 1. Benchmark.

Let $V_{h}$ denote the households' welfare gain and let $V_{d}$ be the donor's welfare gain accounting for the costs of foreign aid transfers. Panel I of Table 3 shows that the welfare gain is larger for lower values of $\alpha$ since, initially, the economies with the least benevolent governments suffer from the lowest capital stocks and the highest tax rates. As an example take the economy characterized by $\alpha=0.5$ : the welfare gain of households is equivalent to increasing 'No Aid' steady state consumption by 91 percent. The donor's welfare gain is of approximately the same size since only temporary aid transfers are made such that the costs of aid are low.

\subsection{Self-enforcing conditional aid}

Fig. 2 plots the normalized variables describing optimal self-enforcing conditional aid policy to which we refer as 'Aid Policy B'.

First note that the general pattern of foreign aid funds is the same as before: in the short-run the donor transfers high aid funds to stimulate the economy on its transition path to the new steady state. Yet, the quantitative properties are different across political regimes. Less benevolent governments receive permanently larger aid funds. Moreover, foreign aid funds do not revert to zero but remain at a positive value. In return, the lower $\alpha$ the less intense are the conditions imposed on aid flows: the tax rates are higher for less benevolent political regimes. As an example take $\alpha=0.3$ and $\alpha=0.5$. For $\alpha=0.3$ the long-run tax is given by 22 percent compared to 12 percent in the more benevolent political regime. Compared to the 'No Aid' steady state this translates into a percentage reduction of around 60 and 70 percent, respectively. Note that the tax 
Table 3

Welfare gains of foreign aid policies.

\begin{tabular}{|c|c|c|}
\hline & $v_{h}$ & $V_{d}$ \\
\hline \multicolumn{3}{|c|}{ 1. Benchmark } \\
\hline \multicolumn{3}{|c|}{ Aid Policy A } \\
\hline$\alpha=0.7$ & 41.40 & 41.40 \\
\hline$\alpha=0.5$ & 91.09 & 91.08 \\
\hline$\alpha=0.3$ & 184.37 & 184.34 \\
\hline \multicolumn{3}{|c|}{ 11. Conditional Aid } \\
\hline \multicolumn{3}{|c|}{ Aid Policy $B$} \\
\hline$\alpha=0.7$ & 37.79 & 27.01 \\
\hline$\alpha=0.5$ & 65.71 & 47.49 \\
\hline$\alpha=0.3$ & 112.90 & 82.26 \\
\hline \multicolumn{3}{|c|}{ III. Unconditional Aid } \\
\hline \multicolumn{3}{|c|}{ Aid Policy B } \\
\hline$\alpha=0.7$ & 10.45 & 1.82 \\
\hline$\alpha=0.5$ & 12.33 & 0.04 \\
\hline$\alpha=0,3$ & 12.76 & -3.44 \\
\hline
\end{tabular}

Notes: Welfare gains are measured in terms of percentage deviation in certainty-equivalence consumption relative to the 'No Aid' steady state, $V_{h}$ denotes the households' welfare gain while $V_{d}$ denotes the donor's welfare gain. The initial capital stock is assumed to be the 'No Aid' steady state capital stock.

cut in percentage points is larger the lower $\alpha$ : in the long-run the tax is reduced by 33, 27 and 21 percentage points for $\alpha=0.3, \alpha=0.5$ and $\alpha=0.7$, respectively.

To understand this finding, focus on the graph that shows the evolution of the co-state variable $\mu_{t}$ over time. Remember that $\mu_{t}$ measures the binding pattern of the enforcement constraint. Due to foreign aid funds capital grows to its new steady state value. However, the incentives to deviate increase since $D\left(0, k_{t-1}\right)$ is growing with the capital stock. To fulfill the enforcement constraint, $\mu_{\mathrm{t}}$ increases during the early periods and then reaches its steady state value. Note that there is a jump increase in $t=0$. Let $w_{t}$ be the relative weight that the donor puts on $v\left(g_{t}\right)$ :

$$
w_{t}=\frac{\mu_{t}-\alpha \mu_{t}}{1+\alpha \mu_{t}}
$$

$w_{t}$ shows the same pattern. It is evident that for lower values of $\alpha$ the donor has to put a larger relative weight on the utility of the government since these governments have high incentives to deviate from the aid contract. This implies that the donor has to pay permanently larger amounts of foreign aid in return for lower tax cuts. Moreover, the reductions in government consumption are the lowest across the political regimes considered here, see Fig. 2 . Compared to the 'No Aid' steady state government consumption can be decreased by approximately 22 percent for $\alpha=0.3$ while for $\alpha=0.5$ and $\alpha=0.7$ a 35 and 50 percent reduction can be reached, respectively.

However, tax cuts measured in percentage points relative to the 'No Aid' steady state are large for less benevolent governments because, initially, taxes have been on a high level. This explains the substantial effectiveness of aid funds in less benevolent political regimes. It is evident that the huge tax cuts strongly increase investment and stimulate capital accumulation and household consumption increases. The impact is largest for economies that suffer from less benevolent political regimes. E.g. consider $\alpha=0.3$ : the capital stock and household consumption have more than doubled compared to the 'No Aid' steady state.

In the long-run all variables reach a new steady state which is summarized in panel III of Table 2 . In the steady state taxes are reduced to fairly low levels (between 3 and 22 percent) such that the capital stock increases considerably. This is accompanied by increased private consumption. Note that for $\alpha=0.3$ foreign aid payments are the highest and amount to 12 percent of recipients' GDP. They help to decrease the size of the government sector, such that the government consumption share is 34 percent and smaller than the private consumption share of 61 percent. Note that although the percentage changes are largest for $\alpha=0.3$, it is evident that economies that suffer from less benevolent governments are still the poorest.

The positive impact of self-enforcing conditional aid is reflected in the welfare gain summarized in panel 11 of Table 3. The welfare gain is equivalent to raising 'No Aid' steady state consumption up to 38,66 and 113 percent for $\alpha$ equal to $0.7,0.5$ and 0.3 , respectively. These results show that designing aid conditionality in a way that ensures the recipient's cooperation yields huge impacts. There is also a large increase in the donor's welfare though the gain is considerable lower compared to households' welfare reflecting the costs of foreign aid. This is particularly true for low values of $\alpha$, i.e. in cases where aid is given to 'bad' governments.

\subsection{Unconditional aid}

What would have been the impact of aid flows described by 'Aid Policy B' if they would have been unconditionally transferred to the developing economy? Without any conditions imposed on aid flows the recipient government solves 

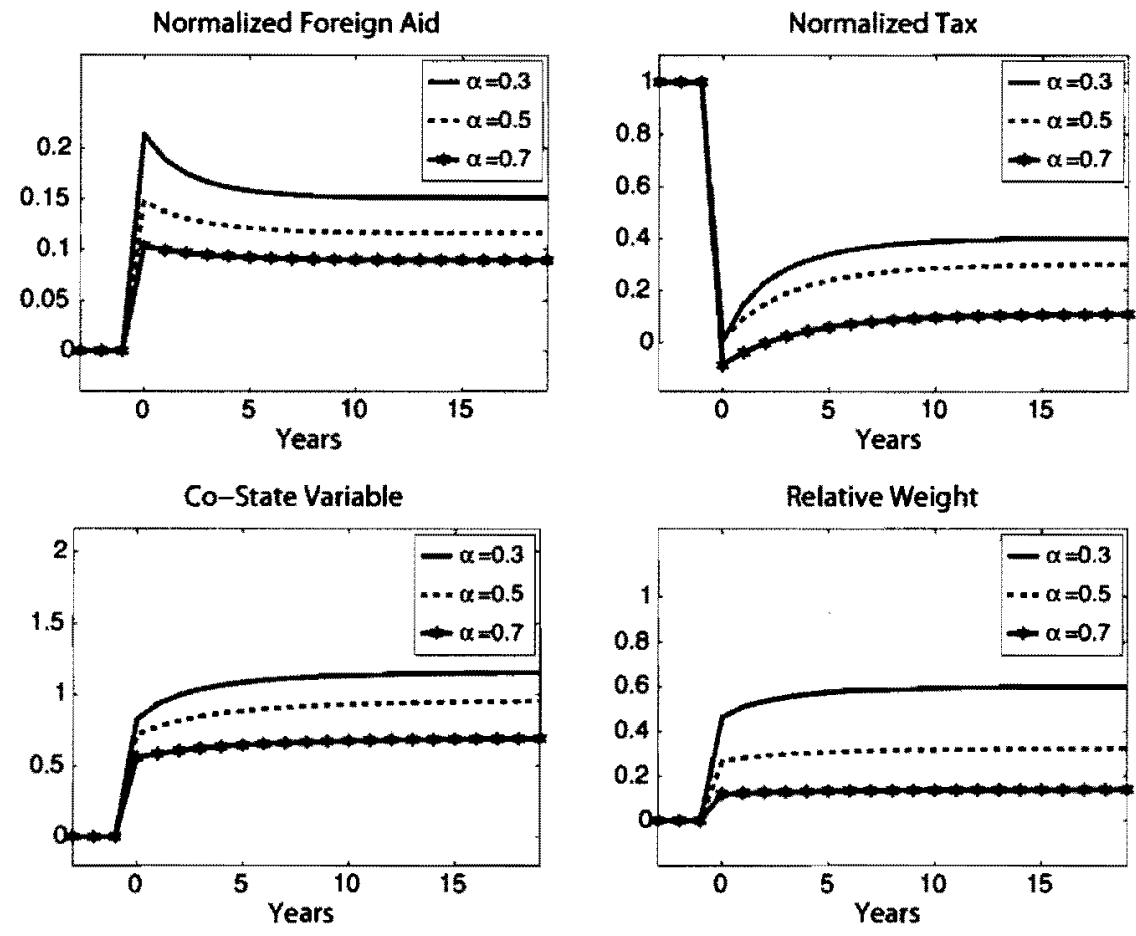

Normalized Household Consumption

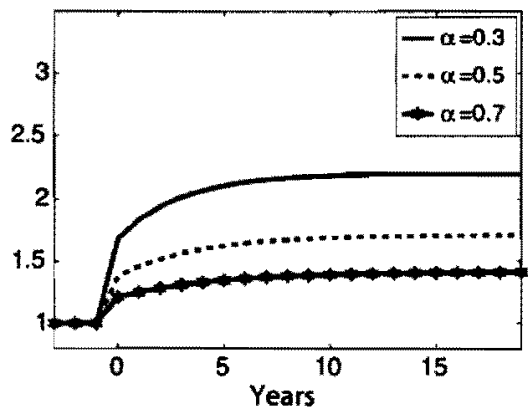

\section{Normalized Government Consumption}

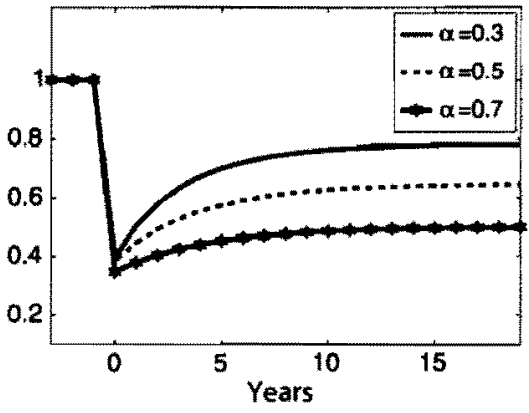

Normalized Investment
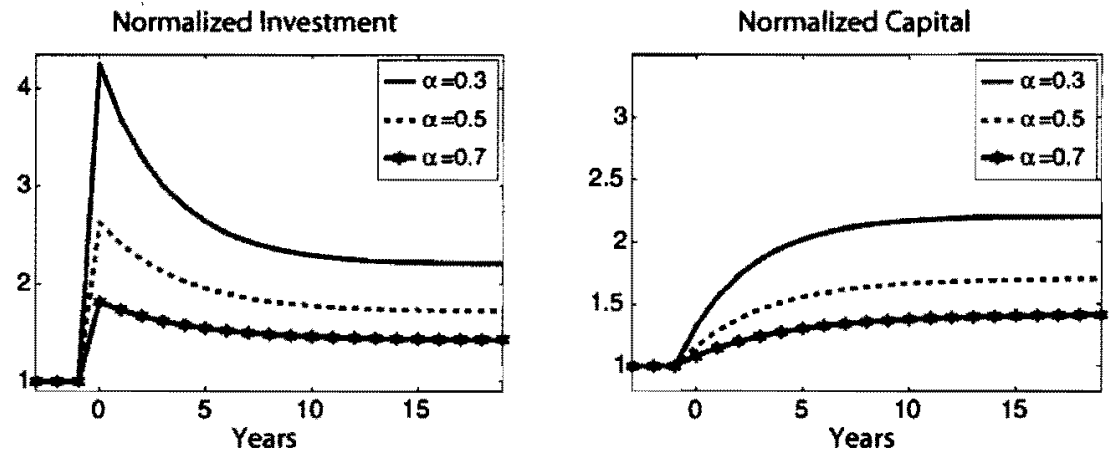

Notes: This figure shows 'Aid Policy B'. The co-state variable $\mu_{\mathrm{t}}$ and the relative weight $w_{t}$ are shown in levels. The tax rate, household consumption, government consumption, investment and capital are normalized by their respective 'No Aid' steady state values. Aid is normalized by the 'No Aid' steady state value of output.

Fig. 2. Self-enforcing conditional aid.

maximization problem (7). Panel IV of Table 2 summarizes the steady states and shows how different political regimes respond to unconditional aid. It is evident that unconditional aid does have a permanent effect, yet, the long-run tax cuts implemented by the recipient government are very limited. Tax reductions are the lowest in the least benevolent political regime. As an example consider the less benevolent political regime described by $\alpha=0.3$. The donor transfers the largest amount of aid in return for the lowest tax cut of 4 percentage points, though the initial 'No Aid' steady state tax level is the highest of the three economies considered here. Tax reductions relative to the 'No Aid' steady state amount to about 
Table 4

Effectiveness of conditional aid.

\begin{tabular}{|c|c|c|c|c|c|c|c|}
\hline & $\bar{W}$ & $\frac{\vec{b}}{y_{\text {roa }}}$ & $\frac{\bar{t}}{\bar{I}_{\text {boadid }}}$ & $\frac{\bar{c}}{\bar{c}_{\text {noald }}}$ & $\frac{\overline{8}}{\overline{8} \text { noald }}$ & $\frac{V_{h}}{v_{b, \text { bench }}}$ & $\frac{v_{d}}{v_{d, b e n d i}}$ \\
\hline \multicolumn{8}{|l|}{ I. Baseline } \\
\hline$\alpha=0.7$ & 0.14 & 0.09 & 0.11 & 1.42 & 0.50 & 0.91 & 0.65 \\
\hline$\alpha=0.5$ & 0.33 & 0.12 & 0.30 & 1.71 & 0.65 & 0.72 & 0.52 \\
\hline$\alpha=0,3$ & 0.61 & 0.15 & 0.40 & 2.20 & 0.78 & 0.61 & 0.45 \\
\hline \multicolumn{8}{|c|}{ 11. Capital Share $\theta=0.5$} \\
\hline$\alpha=0.7$ & 0.12 & 0.09 & 0.01 & 1.53 & 0.50 & 0.99 & 0.71 \\
\hline$\alpha=0.5$ & 0.27 & 0.13 & 0.20 & 1.91 & 0.68 & 0.83 & 0.59 \\
\hline$\alpha=0.3$ & 0.49 & 0.18 & 0.30 & 2.50 & 0.87 & 0.78 & 0.56 \\
\hline
\end{tabular}

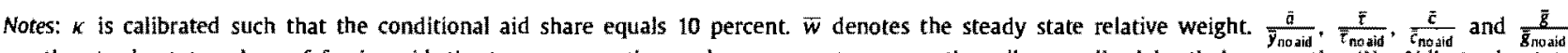
are the steady state values of foreign aid, the tax, consumption and government consumption all normalized by their respective 'No Aid' steady state values, except foreign aid that is nomalized by the 'No Aid' steady state value of output. $\frac{V_{h}}{V_{n} \text { bench }}$ and $\frac{v_{d}}{V_{d, \text { bensh }}}$ are the households' and donor's welfare gains normalized to their respective welfare gains that would occur under the 'Benchmark' aid policy.

25, 13 and 7 percent for $\alpha$ equal to $0.7,0.5$ and 0.3 , respectively. Instead of weakening the tax distortion less benevolent governments use foreign aid to increase unproductive government consumption. Government consumption is raised by 14 , 18 and 24 percent for $\alpha$ equal to $0.7,0.5$ and 0.3 , respectively. Unconditional aid does stimulate the economy, however, the impact on capital and household consumption is rather low given the large amounts of aid. Note that the increases in capital and household consumption relative to the "No Aid" steady state are larger the smaller the value of $\alpha$. This is due to the fact that less benevolent political regimes are poorer in the initial situation and, therefore, receive greater aid funds. If instead we assume that all developing economies receive the same amount of aid, then aid effectiveness is the lowest in the least benevolent political regimes.

Panel III in Table 3 summarizes the effectiveness of unconditional aid in terms of welfare gains measured in households' consumption equivalents. Compared to self-enforcing conditional aid welfare gains are small. In particular the welfare gain of the donor is minimal indicating that the costs of aid are high. If the donor is transferring 'Aid Policy B' to the least benevolent political regime considered here, $\alpha=0.3$, the donor even experiences a welfare loss since the amount of aid is large but the increase in households' welfare is low. Note that such an aid policy would violate the participation constraint of the donor.

\subsection{The capital share}

As discussed in Section 4 we consider a larger capital share as an additional calibration exercise and analyze the properties of optimal self-enforcing conditional aid in an economy characterized by $\theta=0.5$. Without development assistance, the economies associated with $\alpha=0.3, \alpha=0.5$ and $\alpha=0.7$ are characterized by steady state investment shares equal to 19,23 and 28 percent, respectively. In our experiment, to make comparisons possible, we calibrate the cost function parameter $A$ in such a way that in the steady state the recipient's foreign aid share is the same as for $\theta=0.3, i . e . \bar{a} / \bar{y}$ is equal to 8,10 and 12 percent. $^{8}$

Table 4 compares the steady states for $\theta=0.3$ and $\theta=0.5$. We report the relative weight put on utility of government consumption, foreign aid, taxes, household consumption and government consumption. Other than the relative weight. all variables are normalized by their respective 'No Aid' steady state values except foreign aid that is normalized by the 'No Aid' steady state value of output. Moreover, we consider the welfare gains of the households and the donor relative to the respective welfare gains of the 'Benchmark' aid policy.

First, note that the relative weight put on government utility is lower for $\theta=0.5$ than for $\theta=0.3$. The loss of receiving development assistance is larger because foreign aid can be used more effectively in an economy characterized by a larger capital share. Hence, the incentives to deviate from the aid conditions are lower. As a consequence, the tax rates can be substantially reduced and household consumption rises more compared to $\theta=0.3$. The better aid effectiveness is reflected in the welfare gains: for $\theta=0.5$ they are closer to the welfare gains of the "Benchmark' aid policy. Particularly, for $\alpha=0.7$ the welfare gain is nearly the same as under the 'Benchmark' aid policy because aid conditionality generates optimal taxes that are close to zero. Note that the reduction of government consumption is slightly smaller for $\theta=0.5$ although conditionality is less binding: this is due to the somewhat larger normalized aid flows that can be consumed by the government.

\section{Discussion and concluding remarks}

This paper has analyzed the optimal design of incentive compatible aid conditionality and the dynamic properties of the associated aid policies. In a neoclassical framework that accounts for different political regimes, we have argued that sovereign recipient governments may not implement economic policies that coincide with the donors' intention. We have

8 Otherwise foreign aid shares are equal to 3 to 4 percent, and, hence, the increase in consumption and welfare is rather low: 
modeled aid conditionality as an imperfectly enforceable dynamic contract between the donor and the recipient government. Aid conditions have been assumed to be supportable by the threat of a permanent aid cutoff.

We have found that self-enforcing conditional aid strongly stimulates the developing economy. However, aid effectiveness is costly: more aid has to be given to less benevolent political regimes in return for a less intense conditionality.

Since we have adopted a simple model we view our findings as initial benchmark. There are several issues that are worth investigating in greater detail. In the following we provide a brief discussion of some important issues.

\subsection{Off-equilibrium punishment}

Our quantitative findings are based on the assumption that the donor's threat of a permanent aid cutoff is fully credible. However, this may not be the case since the gains that created the original aid contract still exist, i.e. the donor can gain by relaxing the punishment. In an endowment economy with limited enforceable dynamic contracts Cordella et al. (2003) and Kletzer (2005) argue that a renegotiation-proof equilibrium is characterized by aid inflows in punishment that are smaller than those made in equilibrium. If we allow for aid inflows in punishment or relax the assumption of an infinite stay in punishment, the value of the outside option becomes larger. This implies that the recipient government's incentives to deviate increase, and it is likely that the self-enforcing contract is described by larger aid flows and less intense conditionality.

Since we consider a dynamic setting with capital, the specification of renegotiation-proof equilibria is beyond the scope of this paper and we leave the important question concerning the credibility of punishment threats for future research. Instead, in this paper, we argue that since a permanent cutoff from aid is the most severe punishment, the resulting selfenforcing aid contract and the associated welfare gain is the best the donor can achieve. In combination with the assumption that the donor fully commits to future aid policies, we view our scenario as the most optimistic one can think of regarding the effectiveness of aid.

\subsection{Two-sided limited commitment}

In this paper, we have concentrated on enforceability problems due to the behavior of the recipient government and abstracted from time-consistency problems of donors* policies as possible explanation for the failure of conditionality. However, distortions on the donor's side may be important when studying the impact of development assistance. It seems to be a particularly promising avenue for future research to develop a dynamic macroeconomic framework to analyze to what extent limited commitment on the donor's side and time-inconsistency issues serve as explanations for limited aid effectiveness.

As an example consider the stochastic version of the model of this paper. Suppose a positive productivity shock takes place in the developing economy making a permanent aid cutoff a less severe punishment. Hence, in order to prevent the recipient government from breaking the contract, the donor has to increase aid flows in return for a less intense conditionality. ${ }^{9}$ However, as the positive productivity shock dies out, this aid policy might not be incentive compatible for the donor anymore. It would be interesting to analyze the effects of limited commitment on the donor's side, particularly with respect to the volatility of aid flows.

\subsection{Small open economy}

To show the basic characteristics of limited enforceable conditionality as clearly as possible, this paper has analyzed optimal foreign aid in a closed economy setting, although most developing countries are small open economies. In the following we therefore briefly discuss the issues that arise in an open economy context.

Consider a simple version of a small open economy where the country has access to international capital markets and can issue foreign bonds. Furthermore, assume that financial integration is perfect and that there is no default risk, hence, the level of debt is unconstrained. As before, there is a benevolent donor that imposes conditionality on its aid funds, and the off-equilibrium punishment is given by a permanent cutoff from aid.

Suppose the economy is initially in its 'No Aid' steady state. Then, since the capital stock is below its steady state that is reached in the presence of aid flows, the country instantly borrows and invests $\bar{k}-\bar{k}_{\text {noaid }}$ at the world interest rate. Therefore, the economy directly jumps to the steady state of the closed economy discussed in this paper.

So far, we have assumed that the off-equilibrium punishment is a permanent cutoff from aid. In a small open economy with access to foreign bonds, one might argue that direct sanctions such as trade sanctions or the seizure of foreign bonds can be imposed. Then, the off-equilibrium punishment threat is more severe such that the tax policy and the allocation get closer to the first best.

However, particularly in developing countries, financial frictions may constrain domestic demand for foreign bonds. of specific importance may be sovereign risk, i.e. countries may default on their debt contracts. In this context, one issue that

\footnotetext{
${ }^{9}$ Note that this implies that the correlation between foreign aid flows and output is positive, as also noted by Cordella et al. (2003). Pallage and Robe (2001) provide some empirical evidence in favor of this finding.
} 
arises is the debt limit, i.e. the level of debt that can be safely lend by the creditors. It seems particularly interesting to analyze whether debt relief or aid is the better instrument of development assistance. Debt relief might be superior since developing countries could regain access to international financial markets, see also Cordella et al. (2003).

It is well known from the literature on sovereign debt that foreign lenders have only limited powers to directly sanction sovereign borrowers. Here, it would be interesting to introduce uncertainty and a motive for consumption smoothing and focus on reputation as motive for repayment, i.e. if countries default on their debt they are punished by a e.g. permanent exclusion from international financial markets. ${ }^{10}$ Moreover, to make off-equilibrium punishments more severe, a permanent cutoff from aid could be considered. There are potentially important interactions of the two sources of limited commitment that seem to be worth investigating.

\subsection{Other extensions}

Another interesting direction is to study the dynamic macroeconomic effects of informational asymmetries regarding recipient government types. In our analysis so far, we have assumed that the donor has perfect information about the recipient's degree of benevolence. However, the optimal self-enforcing conditional aid flows generate a somewhat perverse incentive for the recipient to pretend to be a 'bad' government. The question then is: how do hidden government types influence the dynamic properties of self-enforcing conditional aid flows?

Other possible extensions of this research are the following. It could be interesting to include alternative tax schemes and government investment in the current setup. Moreover, it seems to be promising to introduce several recipient countries to analyze aid selectivity. Similarly, a multi-donor setup can give insights about coordination among donors. Another avenue of research is to think about different donor instruments, e.g. tied aid projects. All these points are, however, left for future research.

\section{Acknowledgments}

I am especially grateful to Harald Uhlig and two anonymous referees for many suggestions and comments. Moreover, I am indebted to Michael Burda for very helpful discussions. I thank Mathias Trabandt, Christian Stoltenberg, Ralf Brüggemann, Carsten Trenkler, Mirko Wiederholt and seminar participants at Humboldt-University Berlin, University of Mannheim, at the ECB, the 2006 SED meetings in Vancouver, the 2006 EEA meetings in Vienna and the 2006 German Workshop in Macroeconomics in Frankfurt for helpful comments. Financial support by the National Research Center SFB 649 is gratefully acknowledged. All errors are mine.

\section{Appendix A. Numerical solution}

In this appendix we describe the numerical algorithm. Since there is no uncertainty we use a backward procedure to solve for the transitional dynamics. ${ }^{11}$

\section{A.1. Unconditional aid}

Considering the case of unconditional aid, the equilibrium is characterized by Eqs. (2), (4), (6), (8), (9) and (10). To make the system of equations finite dimensional we assume that the economy converges to the steady state in finitely many periods $T+1$. Hence, as time starts in $t=0$, in period $T$ the state variables are given by their steady state values, $k_{T}=\bar{k}$ and $\lambda_{T}=\bar{\lambda}$. Given the initial values $k_{-1}$ and $\lambda_{-1}$, we need to solve for $\left\{c_{t}, g_{t}, \tau_{t}, \zeta_{t}\right\}_{t=0}^{T}$ and $\left\{k_{t}, \lambda_{t}\right\}_{t=0}^{T-1}$. To do so, we consider the equilibrium conditions (2), (4), (8) and (9) for $t=0, \ldots, T$ and the equilibrium conditions (6) and (10) that look forward to $t+1$ for $t=0, \ldots, T-1$. Since we have as many unknowns as equations the system of nonlinear equations can be solved by employing a nonlinear numerical solver.

\section{A.2. Self-enforcing conditional aid}

The absence of uncertainty implies that the enforcement constraint is always binding until the steady state is reached. Hence, we can employ the same solution strategy as described in A.1. The terminal values of the state variables at time $T$ are given by their steady state values, $k_{T}=\bar{k}, \lambda_{T}=\bar{\lambda}_{T}$ and $\mu_{T}=\bar{\mu}$. Given the initial values $k_{-1}, \lambda_{-1}$ and $\mu_{-1}$, to solve for $\left[c_{t}, g_{t}, \tau_{t}, a_{t}, \zeta_{t}\right\}_{t=0}^{T}$ and $\left\{k_{t}, \lambda_{t}, \mu_{t}\right\}_{t=0}^{T-1}$ we use the equilibrium conditions (2), (4), (14), (15) and (16) for $t=0, \ldots, T$ and the forward looking equilibrium conditions $(6),(17)$ and $(18)$ for $t=0, \ldots, T-1$. Note that the enforcement constraint requires the calculation of the default value $D\left(0, k_{t-1}\right)$ according the procedure described in $A .1$.

\footnotetext{
10 Without uncertainty no lending is supportable because as soon as the country reaches its steady state exclusion from financial markets would not pose any threat anymore. Hence, countries have no incentive to fulfill their debt contract. Lenders anticipate this and no lending is supportable.

11 Our procedure follows e.g. Trabandt (2007).
} 


\section{References}

Adam, C., o'Connell, S., 1999. Aid, taxation and development in sub-saharan Africa. Economics and Politics 11 (3). 225 -253.

Alvarez, $F_{n}$ Jermann, $\mathrm{U}_{\mathrm{J}}, 2000$. Eficiency, equilibria, and asset pricing with risk of default. Econometrica 68 (4), 775-798.

Arellano. C., Bulîr, A., Lane, T., Lipschitz, L., 2009. The dynamic implications of foreign aid and its variability. Journal of Development Economics 88 (1), $87-102$.

Azam, J.-P., Laffont, J.-I, 2003. Contracting for aid. Journal of Development Economics 70, 25-58.

Boone, P. 1996. Politics and the effectiveness of foreign aid. European Economic Review 40 (2), 289-329.

Burnside, C., Dollar, D., 2000. Aid policies and growth. The American Economic Review 90 (4), 847-868.

Burnside, C., Dollar, D., 2004. Aid, policies and growth: Revisiting the evidence. World Bank Policy Research Working Paper 3251.

Chatterjee, S., Sakoulis, G., Turnovsky, S.]., 2003. Unilateral capital transfers, public investment and economic growth. European Economic Review 47 (6), $1077-1103$.

Chenery, H.B., Strout, A.M., 1966. Foreign assistance and economic development. The American Economic Review 56 (4), $679-733$.

Coate, S., Morris, S., 1995. Policy conditionality. Mimeo. University of Pennsylvania.

Collier, P. Dollar, D., 2001. Can the world cut poverty in half? How policy reform and effective aid can meet international development goals. World Development $29(11), 1787-1802$

Collier, P., Dollar, D., 2002. Aid allocation and poverty reduction. European Economic Review 46 (8), 1470-1500.

Cooley, T., Marimon, R., Quadrini, V., 2004. Aggregate consequences of limited contract enforceability. Journal of Political Economy 112 (4). $817-847$.

Cordella, T., Dell'Ariccia, G., Kletzer, K.M., 2003. Conditional aid, sovereign debt, and debt relief. Mimeo. University of California, Santa Cruz.

Dalgaard, $C-1,2008$. Donor policy rules and aid effectiveness. Journal of Economic Dynamics and Control 32, $1895-1920$.

Dalgaard, C-1., Hansen, $H_{4}$, 2001. On aid, growth and good policies. Journal of Development Studies 37 (6), $17-41$.

Dalgaard, C.-J., Hansen, H., Tarp, F, 2004. On the empirics of foreign aid and growth. Economic Journal 114, 191-216.

Devarajan, S., Dollar, D., Holmgren, T. (Eds.), 2000. Aid and Reform in Africa: Lessons from Ten Case Studies. World Bank, Washington DC.

Dollar, D., Svensson, J., 2000. What explains the success or failure of structural adjustment programmes? The Economic Journal 110 (127), 894-917.

Easterly, W., 2001. The Elusive Quest for Growth. MIT Press, Cambridge, MA.

Easterly, W., 2003. Can foreign aid buy growth? Journal of Economic Perspectives 17 (3), 23-48.

Easterly, W., Levine, R., Roodman, D., 2004. New data, new doubts: A comment on Burnside and Dollar's 'Aid Policies and Growth (2000), The American Economic Review 94 (3), 774-780.

Federico, $G_{n}, 2001$. Samaritans, rotten kids and policy conditionality. Mimeo. Nuffield College Oxford.

Giovannetti. G.. Marcet. A., Marimon, R., 1993. Growth, capital flows and enforcement constraints. European Economic Review 37 (2), $418-425$.

Gollin, D., 2002. Getting income shares right. Journal of Political Economy $110(2), 458-474$.

Gourinchas, $\mathrm{P}, \mathrm{O}_{*}$ Jeanne, $\mathrm{O}, 2008$. Capital flows to developing countries: The allocation puzzle. Mimeo. University of California at Berkeley.

Guillaumont, $P_{*}$ Chauvet, L., 2001. Aid and performance: A reassessment. Journal of Development Studies 37 (6), 66-92.

Hagen, R.J. 2006. Samaritan agents? On the delegation of aid policy. Journal of Development Economics 79 (1), $249-263$.

Hansen, $H_{*}$, Tarp, F. 2000. Aid effectiveness disputed. Journal of International Development 12 (3). 375-398.

Hansen, H., Tarp, F., 2001. Aid and growth regressions. Journal of Development Economics 64 (2), $547-570$.

Kehoe, T.l. Levine, D.K., 1993. Debt-constrained asset markets. The Review of Economic Studies $60,865 \sim 888$.

Kehoe, T.J., Levine, D.K., 2001. Liquidity constrained markets versus debt constrained markets. Econometrica 69 (3), 575 598.

Kehoe, P.J., Perri, F., 2002. International business cycles with endogenous incomplete markets. Econometrica 70 (3), $907-928$.

Kletzer, K., 2005. Aid and sanctions. Mimeo. University of California, Santa Cruz.

Kletzer, K., Wright, B,D., 2000. Sovereign debt as intertemporal barter. The American Economic Review 90 (3), $621-639$.

Kocherlakota, N., 1996. Implications of efficient risk sharing without commitment. The Review of Economic Studies 63 (4), $595-609$.

Krüger, D., Perri, F, 2006. Does income inequality lead to consumption inequality? Evidence and theory. The Review of Economic Studies 73 (1), 163-193.

Kruger, D., Uhlig. H., 2006. Competitive risk sharing contracts with one-sided commitment. Journal of Monetary Economics 53 (7), $1661-1691$.

Lensink, R., White, H., 2001. Are there negative returns to aid? Journal of Development Studies 37 (6), 42-65.

Ligon. E., Thomas, J.P., Worrall. T., 2000. Mutual insurance, individual savings, and limited commitment. Review of Economic Dynamics 3, $216-246$.

Marcet, $A_{2}$ Marimon, $R_{n}$ 1992. Communication, commitment, and growth. Journal of Economic Theory 58, $219-249$.

Marcet, A., Marimon, R., 1998. Recursive contracts. Mimeo. Universitat Pompeu Fabra, Barcelona.

Mourmoras, A., Rangazas, P., 2006. Foreign aid policy and sources of poverty: A quantitative framework. IMF Working Paper WP/06/014.

Murshed, M., Sen, S., 1995. Aid conditionality and military expenditure reduction in developing countries: Models of asymmetric information. Economic Journal $105,498-505$.

Pallage, S. Robe, M. 2001. Foreign aid and the business cycle. Review of International Economics 9 (4), 495-517.

Pedersen, K.R., 1996. Aid, investment and incentives. Scandinavian Journal of Economics $98,423-438$.

Pedersen, K.R., 2001. The samaritan's dilemma and the effectiveness of foreign aid. International Tax and Public Finance 8, 693-703.

Svensson, J., 1999. Aid, growth and democracy. Economics and Politics 11 (3), 275-297.

Svensson, $J_{2}, 2000 \mathrm{a}$. Foreign aid and rent-seeking, Journal of International Economics 51 (2), 437-461.

Svensson, J., 2000b. When is foreign aid policy credible? Aid dependence and conditionality, Journal of Development Economics 61 (1), $61-84$.

Svensson, J, 2003. Why conditional aid does not work and what can be done about it? Journal of Development Economics 70 (2), $381-402$.

Trabandt, M., 2007. Optimal pre-announced tax reform. Mimeo. Sveriges Riksbank. 